\title{
RELATION BETWEEN SLEEP QUALITY AND METABOLIC SYNDROME AMONG UNIVERSITY STUDENTS ${ }^{1}$
}

\author{
Márcio Flávio Moura de Araújo², Roberto Wagner Júnior Freire de Freitas ${ }^{3}$, Adman Câmara Soares Lima \\ Dayse Cristina Rodrigues Pereira ${ }^{5}$, Maria Lúcia Zanetti ${ }^{6}$, Marta Maria Coelho Damasceno ${ }^{7}$
}

\footnotetext{
${ }^{1}$ Article extracted from the thesis titled - University students' sleep quality and its interface with metabolic syndrome and health indicators, presented to the Postgraduate Program in Nursing, Universidade Federal do Ceará (UFC), in 2012. Research financed by the National Council for Scientific and Technological Development (CNPq), through Universal Bid for Tenders MCT/CNPq 14/2009, process 474902/2009-9.

${ }^{2}$ Ph.D. in Nursing. Professor of the Nursing Course of the Universidade da Integração Internacional da Lusofonia Afro-Brasileira. Acarape, Ceará, Brazil. E-mail: marciofma@unilab.edu.br

${ }^{3}$ Ph.D. in Nursing. Researcher at the Fundação Oswaldo Cruz (FIOCRUZ). Professor of the Nursing Course of the Universidade Federal do Piauí. Floriano, Piauí, Brazil. E-mail: robertowjff@globo.com

${ }^{4}$ M.Sc. in Nursing. Professor of the Nursing Course of the Faculdade de Educação e Cultura do Ceará. Fortaleza, Ceará, Brazil. E-mail: adminhacs@hotmail.com

${ }^{5}$ M.Sc. in Nursing. Professor of the Nursing Course of the Faculdade de Juazeiro do Norte. Juazeiro do Norte, Ceará, Brazil. E-mail: dayse.dcrp@hotmail.com

${ }^{6}$ Ph.D. in Nursing. Associate Professor of the Escola de Enfermagem de Ribeirão Preto of Universidade de São Paulo. Ribeirão Preto, São Paulo, Brazil. Email: zanetti@eerp.usp.br

${ }^{7}$ Ph.D. in Nursing, Professor of the Postgraduate Program in Nursing of the UFC. Fortaleza, Ceará, Brazil. E-mail: martadamasceno@terra.com.br
}

\begin{abstract}
This transversal study aimed to analyze the relationship between poor sleep quality and metabolic syndrome among university students. The sleep quality and the components of metabolic syndrome of 701 university students from Fortaleza, Brazil, were evaluated during 2011 and 2012. In the evaluation of the scale of the associations, robust Poisson regression was used, adjusted for sex and age. The prevalence of metabolic syndrome and poor quality sleep was $1.7 \%$ and $95.3 \%$ respectively. There was an increase in risk of $5 \%$ of developing metabolic syndrome among those university students who slept poorly ( $\mathrm{p}=0.013$ ). It is concluded that the university students in the sample who were poor sleepers present a greater probability of presenting metabolic syndrome.
\end{abstract}

DESCRIPTORS: Glucose metabolism disorders. Sleep. Students.

\section{RELAÇÃO ENTRE QUALIDADE DO SONO E SÍNDROME METABÓLICA EM UNIVERSITÁRIOS}

RESUMO: Estudo de corte transversal, cujo objetivo foi analisar a relação entre má qualidade do sono e síndrome metabólica em universitários. Foram avaliados a qualidade do sono e os componentes da síndrome metabólica de 701 universitários de Fortaleza, Brasil durante 2011 e 2012. Na avaliação da magnitude das associações foi utilizada a regressão de Poisson robusta ajustada para sexo e idade. A prevalência de síndrome metabólica e má qualidade do sono foi de 1,7\% e 95,3\% respectivamente. Houve um aumento do risco de $5 \%$ para o desenvolvimento de síndrome metabólica entre os universitários maus dormidores ( $\mathrm{p}=0,013$ ). Pode-se concluir que os universitários da amostra maus dormidores apresentaram mais chance de apresentar síndrome metabólica.

DESCRITORES: Transtornos do metabolismo de glucose. Sono. Estudantes.

\section{RELACIÓN ENTRE CALIDAD DEL SUEÑO Y SÍNDROME METABÓLICO EN ESTUDIANTES UNIVERSITARIOS}

RESUMEN: Estudio cuantitativo, transversal, con el objetivo de analizar la relación entre la calidad del sueño de los pobres y el síndrome metabólico en estudiantes universitarios. Durante 2011 y 2012 se evaluaron la calidad del sueño y los componentes del síndrome metabólico de 701 estudiantes universitarios en Fortaleza, Brasil. En la evaluación de la magnitud de las asociaciones se utilizó robusto de regresión de Poisson ajustado por edad y sexo. La prevalencia del síndrome metabólico y la mala calidad del sueño fue de 1,6\% y 95,3\% respectivamente. Hubo un aumento del 5\% de riesgo de desarrollar el síndrome metabólico entre los universitarios malos durmientes $(p=0,013)$. Se puede concluir en la investigación que los estudiantes universitarios clasificados como malos durmientes eran más propensos a tener el síndrome metabólico.

DESCRIPTORES: Trastornos del metabolismo de la glucosa. Sueño. Estudiantes.

Text Context Nursing, Florianópolis, 2015 Abr-Jun; 24(2): 505-12. 


\section{INTRODUCTION}

Metabolic syndrome (MetS) is an aggregation of cardiometabolic problems, characterized by a rise in arterial pressure (AP), fasting venous blood glucose (FVBG), plasma triglycerides (PT), abdominal circumference (AC) and reduction in the levels of high density lipoprotein-cholesterol (cholesterol) (HDL-C). This may or may not be accompanied by the use of antidiabetic, antilipemic and anti-hypertensive medications. Today, approximately $40 \%$ of North Americans, $30 \%$ of Europeans and $20-30 \%$ of Asians are affected by MetS ${ }^{1-3}$ while in Africa and the Middle East, there are publications indicating prevalences of $25 \%$ and $20.4 \%$ for this metabolic disorder, respectively. ${ }^{4-5}$ In Brazil, general epidemiological data on the prevalence of MetS do not yet exist, although a recent review estimated the prevalence of MetS in Brazil at between $14.9 \%$ and $65.3 \%{ }^{6}$

MetS is responsible for approximately $7 \%$ of deaths worldwide, regardless of cause, as it significantly increases the chances of cardiovascular diseases (CVD), and cerebrovascular diseases, type II diabetes, non-alcoholic hepatic steatosis, cancer and Parkinson's disease. Today, one in five young adults (20-30 years old) will develop MetS, depending on their lifestyles. As a result, $10 \%$ of the world population in this age range will be vulnerable to developing the cardiometabolic complications associated with MetS.7-8

Besides the classic diagnostic criteria cited above, some studies have suggested the participation of other factors, such as cardiovascular and inflammatory markers, pro-thrombotic substances, and sleep deprivation as precursors of MetS. These factors, however, remain highly controversial and were not included in any of the diagnostic criteria for MetS. ${ }^{9-13}$

There is robust evidence in the literature that imbalances in the sleep-wakefulness cycle act as a risk factor for developing MetS. Epidemiological data have shown, over the last century, a reduction in humanity's sleep quality. This occurs voluntarily so that people can work or enjoy leisure time. In parallel, there has also been an increase in some of the main components of MetS, namely: insulin resistance and obesity. Poor sleep quality, furthermore, seems to be related to hyperphagia, loss of mean mass, and increase in risk for dyslipidemias. ${ }^{9,11-13}$

Among people who simultaneously present sleep problems and MetS, the chances of developing coronary artery disease increase by a factor of three. Among those who have both MetS and sleep apnea syndrome, there is a worse prognosis in inflammatory markers, uric acid and in the other components of MetS. ${ }^{14-16}$

Other aspects referent to poor sleep quality, such as snoring, sleep apnea, excessive daytime somnolence, working at night, and restless legs syndrome also seem to increase peoples' vulnerability regarding MetS. ${ }^{15,17}$ However, the authors consulted emphasized that investigations on the relation between sleep quantity and quality and MetS remain incipient, mainly in the young population. This is concerning, as the modulation of sleep in children can have future repercussions on these subjects' health. ${ }^{15-19}$

There is a considerable number of publications focusing on the relation between duration of sleep and the presence of MetS and its components, either aggregated or in isolation. Nevertheless, the relation between the simultaneous presence of MetS and poor sleep quality still requires a greater amount of research. To our knowledge, there are only eight studies on the above-mentioned relation; however, all were undertaken outside Brazil and with people of middle age, adults, older adults, and adolescents. ${ }^{9,12,14,20-24}$ Thus, this relation has not yet been analyzed in young adults, or among Brazilians. As a result, this article's objective was to analyze the relation between sleep quality and the prevalence of MetS in university students of Fortaleza, in the state of Ceará (CE), Brazil.

\section{METHOD}

A transversal study, undertaken in 2011 and 2012 at the Universidade Federal do Ceará. The target population was undergraduate students of both sexes, properly enrolled in the campuses of Fortaleza, Brazil. At the time of the study, the total number of students registered in the above-mentioned institution was 17,228 subjects, distributed in six major areas of knowledge: the Humanities, the exact sciences, the agricultural sciences, the health sciences, the technological sciences and sciences.

The sample calculation was based on a formula for infinite populations. A percentage of $50 \%$ was adopted $(\mathrm{P}=50 \%$ and $\mathrm{Q}=50 \%)$, given that this value provides a maximum sample size, when the level of significance $(\alpha=0.05)$ and the relative sample error of $8 \%$ are fixed (absolute error $=4 \%$ ). The sample size resulted in 600 subjects. A rate was calculated of $10 \%$ loss of information in questionnaires through incorrect and/or incomplete responses. 
The following were used as inclusion criteria: to be a correctly enrolled university student in the on-site undergraduate courses run during the day; to live in Fortaleza, Brazil; and to have telephone and email for contact. University students who were pregnant were excluded.

From each one of the six areas of knowledge in the above-mentioned university, two undergraduate courses were selected, for convenience. However, in some academic units it was necessary to include more courses in order to complete the sample established. Among these, students from different academic semesters were selected for convenience; these were invited to participate in the study in the classroom, following explanation of the study's methods and objectives. It should be highlighted that, during data collection, students from different courses attended a class in a single group, independently of the academic unit visited.

Data collection took place between March and June 2011 and February and March 2012. All the stages of the data collection were undertaken by four nurses, who had previously undergone 16 hours' training to be familiarized with the instruments, with a view to ensuring quality in the checking of the measurements.

The evaluation of the sociodemographic data and data on sleep quality, undertaken through a structured questionnaire, took place at times distinct from those of collection of clinical data. In this stage, systolic arterial pressure (SAP), diastolic arterial pressure (DAP) and AC were measured; biochemical data were collected.

Sleep quality was analyzed based on a version of the Pittsburgh Sleep Quality Index (PSQI) validated, translated and adapted to Brazilian standards. The above-mentioned version evidenced a high degree of internal consistency (Cronbach alpha $=0.82$ ) and was demonstrated to be equivalent to its respective original. The university students with scores of over five points were classified as poor sleepers. ${ }^{25}$

In order to check AP, aneroid sphygmomanometers of the Tycos ${ }^{\circledR}$ brand were used, with cuffs of the Welch Allyn ${ }^{\circledR}$ brand, of different sizes, with the cuff width responding to $40 \%$ of the conference of the arm, and the length involving at least $80 \%$. In addition, biauricular stethoscopes of the Littman brand ${ }^{\circledR}$ were used for auscultation. It is worth emphasizing that all these instruments were bought at the time of data collection and were calibrated. Three measurements were taken, with a minimum interval of one minute between each, and the mean of the last two measurements was calculated as the student's arterial blood pressure value.

The study participants fasted for 12 hours for the biochemical determination of FVBG, PT and HDL-C. The vacuum collection system $B D$ Vacutainer $^{\circledR}$ was used in the venous puncture, and commercial kits from Labtest Diagnostics S/ $\mathrm{A}^{\circledR}$ were used in the measurement of FVBG, PT and HDL-C. The concentrations were determined using the Labmax $240^{\circledR}$ automatic biochemical analyzer.

During the process of checking the components of MetS and their detection among the university students, the guidelines of the National Cholesterol Education Program Expert Panel on Detection, Evaluation, and Treatment of High Blood Cholesterol in Adults (Adult Treatment Panel III) were adopted. ${ }^{26}$

The data were entered using double keying on an Excel ${ }^{\circledR}$ spreadsheet, and were subsequently exported to the STATA statistical software, version 8.0. The double keying was undertaken so as to detect incorrect, incomplete or absent information in the study's database. The analysis of the data was preceded by the descriptive-exploratory study of the sociodemographic characteristics, the components of MetS, and the variables related to sleep quality, through the use of uni- and bi-variate frequencies for the qualitative variables, and the generation of means of central tendency for the quantitative variables.

In order to ascertain the differences between the proportions of the components of MetS and the PSQI indicated, the Pearson Chi-squared test or Fisher's exact test were used (when necessary). In order to analyze the relation between the quantitative variables (FVBG, SAP, DAP, AC, PT, HDL-C), sleep quality, and the PSQI score, the Mann-Whitney test and Spearman linear correlation $\left(r_{s}\right)$ were adopted, respectively.

In order to estimate the scale of the association, the prevalence of the PSQI and MetS was used as a measure of frequency. As a measure of association, the researchers used the Prevalence Ratio (PR) and its respective confidence intervals at $95 \%$, estimated as a function of the relative risk (RR) of the robust Poisson regression. In all the analyses, a level of significance of $\mathrm{p} £ 0.05$ was adopted. The associations were adjusted according to age and sex. The indication for use of the robust Poisson regression, in this study, was a result of the high prevalence qualities found in the study population $(95.3 \%) .{ }^{27}$ 
This study was approved by the Committee for Ethics in Research with Human Beings, of the Health Sciences Center of the Universidade Federal do Ceará, under protocol N. 208/2010.

\section{RESULTS}

The study sample was made up of 701 university students from six areas of knowledge, distributed in 24 undergraduate courses. However, only 667 students filled out the statements correctly and/or participated in all the stages of the methodology. Women predominated $(62.6 \%)$ and the mean age of the sample was 21.5 years ( $\mathrm{SD} \pm 4.5$ years).

In relation to race, the university students stated that they were of mixed black and white descent $(50.6 \%)$, white $(36.1 \%)$, black $(7.8 \%)$ and Asian (5.6\%). Regarding the area of knowledge, the participants were distributed in the following way: human sciences $(20.4 \%)$, sciences $(18.5 \%)$, exact sciences $(16.5 \%)$, technological sciences (16\%), health sciences $(15 \%)$ and agricultural sciences $(13.6 \%)$. Students who were in the third $(20.8 \%)$ and the first semester $(19.5 \%)$ predominated.

The majority of the students were single (93\%), lived with their parents $(71.2 \%)$, and only studied $(65.2 \%)$. The students were mainly from socioeconomic classes C (39.6\%) and B (39.7\%), considered to have median purchasing power in Brazil. These students live with a monthly family income of US\$1,705 (SD $\pm U S \$ 200)$. It is important to emphasize that $15 \%$ of the participants did not state the value of their monthly income.

The value of $\mathrm{AC}$ was elevated in $5.4 \%$ of the students, while only $3.0 \%$ of the participants were classified as hypertensive. The participation of students using antihypertensive, oral antidiabetic or antilipemic drugs was not detected. The prevalence of poor quality sleep was $95.3 \%$, which made the event studied a common outcome.

The university students who slept well presented greater values of normality for PT $(82 \%)$, HDL-C (91\%), FVBG (87.8\%) and AP (94\%) in relation to the students who slept badly. These presented a higher percentage $(94.6 \%)$ for normal AC in relation to those who slept well (91\%). However, these proportional differences between good and poor sleepers and the components of MetS were not statistically significant (Table 1).

The prevalence of MetS in the study population was below $2 \%$. We did not identify statistically significant proportional differences between the groups in relation to the prevalence of MetS $(p=1.000)$ (Table 1). However, all the participants with MetS were classified as poor sleepers.

Table 1 - Characteristics of the components of metabolic syndrome in relation to sleep quality (n=701). Fortaleza-CE, Brazil, 2012

\begin{tabular}{|c|c|c|c|}
\hline Components of Metabolic Syndrome & $\begin{array}{c}\text { Good sleepers } 33(4.7) \\
\text { n (\%) }\end{array}$ & $\begin{array}{c}\text { Poor sleepers } 668(95.3) \\
\text { n }(\%)\end{array}$ & p-value* \\
\hline \multicolumn{4}{|l|}{ Abdominal Circumference $(n=700)$} \\
\hline Normal & $30(91.0)$ & $631(94.6)$ & 0.421 \\
\hline Raised & $3(9.0)$ & $36(5.4)$ & \\
\hline \multicolumn{4}{|l|}{ Triglycerides $(n=690)$} \\
\hline Normal & $26(78.7)$ & $505(76.8)$ & 1.000 \\
\hline Raised & $7(21.3)$ & $152(23.2)$ & \\
\hline \multicolumn{4}{|l|}{ HDL-C† $(n=690)$} \\
\hline Normal & $30(91.0)$ & $575(87.5)$ & 0.787 \\
\hline Low & $3(9.0)$ & $82(12.5)$ & \\
\hline \multicolumn{4}{|l|}{ Fasting Venous Glycemia $(n=691)$} \\
\hline Normal & $29(88)$ & $577(87.7)$ & 1.000 \\
\hline Raised & $4(12)$ & $81(12.3)$ & \\
\hline \multicolumn{4}{|l|}{ Arterial Pressure $(n=700)$} \\
\hline Normal & $31(94.0)$ & $611(91.6)$ & 1.000 \\
\hline Raised & $2(6.0)$ & $56(8.4)$ & \\
\hline \multicolumn{4}{|l|}{ Metabolic Syndrome $(\mathrm{n}=690)$} \\
\hline No & $33(100.0)$ & 645 (98.3) & 1.000 \\
\hline Yes & - & $12(1.7)$ & \\
\hline
\end{tabular}

"Fisher's exact Chi-squared test; † High density lipoprotein-cholesterol. 
Table 2 presents the scale of the associations found between the components of MetS and poor sleep quality. In accordance with adjustments for age and sex, a statistically significant, positive raw association was found between the presence of MetS and poor sleep quality. That is, among the university students who slept badly, there was a $5 \%$ increase in risk of developing MetS (PR=1.05). On the other hand, we observed that the university students who slept badly had the same probability of presenting raised FVBG $(\mathrm{PR}=1.00)$ (Table 2).

Table 2 - Association between the components of metabolic syndrome and poor sleep quality among university students (n=701). Fortaleza-CE, Brazil, 2012

\begin{tabular}{|c|c|c|c|}
\hline Components of Metabolic Syndrome & $\begin{array}{l}\text { Prevalence in the } \\
\text { group } n(\%)\end{array}$ & $\mathbf{P R}^{*}$ & CI 95\%* \\
\hline Prevalence of metabolic syndrome in the study population $(n=690)$ & 1.7 & & \\
\hline \multicolumn{4}{|l|}{ Abdominal circumference $(n=700)$} \\
\hline Normal & 95.4 & 1.00 & -- \\
\hline Raised & 92.3 & 0.98 & $0.91-1.06$ \\
\hline \multicolumn{4}{|l|}{ Triglycerides 690) } \\
\hline Normal & 95.1 & 1.00 & -- \\
\hline Raised & 95.6 & 1.00 & $0.95-1.04$ \\
\hline \multicolumn{4}{|l|}{ HDL-C $†(n=690)$} \\
\hline Normal & 95.0 & 1.00 & -- \\
\hline Low & 96.4 & 1.02 & $0.97-1.07$ \\
\hline \multicolumn{4}{|l|}{ Glycemia $(n=691)$} \\
\hline Normal & 95.2 & 1.00 & -- \\
\hline Raised & 95.2 & 1.00 & $0.95-1.02$ \\
\hline \multicolumn{4}{|l|}{ Arterial pressure $(n=700)$} \\
\hline Normal & 95.1 & 1.00 & -- \\
\hline Raised & 96.6 & 1.00 & $0.95-1.06$ \\
\hline \multicolumn{4}{|l|}{ Metabolic syndrome $(\mathrm{n}=690)$} \\
\hline No & 95.1 & 1.00 & -- \\
\hline Yes & 100.0 & & $1.03-1.07$ \\
\hline
\end{tabular}

*PR=Prevalence Ratio estimated through the robust Poisson regression with adjustments for age and sex; † High density lipoproteincholesterol.

The values of the means and medians of the components of MetS obtained were within the normal limits. This result is expected, in the light of the low prevalence of MetS found in the study population $(1.7 \%)$ (Table 3$)$.

In the comparison between components of MetS among the groups, a raised dispersion and concentration of values above the median point for $\mathrm{AC}$ and $\mathrm{PT}$ and reduction of the median value for DAP were observed among those who slept poorly. Among those who slept well, lower glycemic values were observed. However, statistically significant values were not observed between the continuous values of the components of MetS, according to the classification of sleep quality. Also ascertained were asymmetric distributions for all the measures of the components of MetS in both groups (Table 3 ).

Table 3 - Distribution of the mean ( \pm standard deviation) and median values of the components of metabolic syndrome, according to sleep quality. Fortaleza-CE, Brazil, 2012

\begin{tabular}{lccccccc}
\hline \multirow{2}{*}{ Measurements } & \multicolumn{3}{c}{ Good sleepers } & \multicolumn{3}{c}{ Poor sleepers } \\
\cline { 2 - 7 } & Median & Mean $( \pm \mathbf{s d})$ & CI 95\% & Median & Mean $( \pm$ sd) & CI 95\% & Value $\boldsymbol{p}^{*}$ \\
\hline Abdominal circumference & 74.0 & $\begin{array}{c}76.69 \\
( \pm 2.02)\end{array}$ & $72.5-80.8$ & 77.0 & 78.31 & $77.5-79.0$ & 0.128 \\
Triglycerides & 123.8 & $\begin{array}{c}123.86( \pm 5.67) \\
( \pm 10.1)\end{array}$ & $112.3-135.4$ & 130.0 & $127.52( \pm 32.4)$ & $125.0-130.0$ & 0.517 \\
HDL-C $\dagger$ & 52.0 & $\begin{array}{c}54.70 \\
( \pm 1.38)\end{array}$ & $51.8-57.5$ & 52.6 & 53.69 & $53.1-54.2$ & 0.666 \\
\hline
\end{tabular}




\begin{tabular}{lccccccc}
\hline Systolic pressure & 110.0 & $108.21( \pm 1.83)$ & $104.4-111.9$ & 109.0 & $109.68( \pm 11.9)$ & $108.7-$ & 110.5 \\
& & 71.2 & & & 0.578 \\
Diastolic pressure & 72.0 & $( \pm 1.45)$ & $68.2-74.1$ & 70.0 & 71.05 & $70.4-71.7$ & 0.809 \\
& & & & $( \pm 8.5)$ & 88.70 & $87.8-89.5$ & 0.376 \\
Venous fasting glycemia & 87.0 & $87.0( \pm 1.89)$ & $83.1-90.9$ & 90.0 & $( \pm 10.6)$ & \\
\hline
\end{tabular}

* Mann-Whitney Test; † High density lipoprotein-cholesterol.

Statistically significant differences were not found between sleep duration (in hours) and the measurements of the components of MetS in isolation: $\mathrm{AC}(\mathrm{p}=0.686), \mathrm{PT}(\mathrm{p}=0.223), \operatorname{HDL}-\mathrm{C}(\mathrm{p}=0.638)$, SAP/DAP $(p=0.487)$ and FVBG $(p=0.468)$.

The components of MetS, PT $(\rho=-0.055$; $p=0.1591)$, HDL-C $(\rho=0.025 ; p=0.5096)$, AC $(\rho=-$ $0.033 ; p=0.3821)$, FVBG $(\rho=-0.035 ; p=0.3589)$, SAP $(\rho=-0.034 ; p=0.3761)$ and DAP $(\rho=-0.027 ; p=0.4764)$ did not present a statistically significant correlation with the PSQI indicator.

\section{DISCUSSION}

The prevalence of MetS identified was low, while that of poor sleep quality was a common event in the population. It is worth emphasizing that the worldwide prevalence of MetS varies from $<10 \%$ to up to $84 \%$, depending on the region, the environment (urban or rural), the composition of the population studied (sex, age, race and ethnic group) and on the definition adopted for MetS. ${ }^{6}$ In relation to sleep quality, this may diverge as a result of the natural difference there is between biological age and chronological age. Restorative sleep (slow waves) reduces as biological age advances, this process being more harmful when it occurs among younger people. ${ }^{28}$

In this study, all the subjects affected by MetS were poor sleepers. It was also observed that among the university students who slept badly, there was an increase in the risk of developing MetS of 5\%. No study was found which had analyzed the relation between university students' sleep quality and the prevalence of MetS.

Based in a vast bibliographic survey, in databases such as PubMed, Ulrich, High Wire and Scopus, few publications were found with similar objectives to this article. The few investigations detected and analyzed were undertaken with adults of middle age, adolescents, older adults and people working in specific professions. In spite of this, the above-mentioned studies consulted are unanimous in indicating that quantitative and qualitative changes in sleep present robust epide- miological associations with MetS, in particular, with the components of abdominal obesity and glycemia. ${ }^{9,12,14,20-24}$

The exact mechanism through which sleep can raise the risk for MetS is not yet clear. However, some authors consulted have elaborated hypotheses in order to explain this phenomenon. This vulnerability results from obesity triggered by the poor quality of the sleep. The increase in appetite (due to the rise in ghrelin) and the appearance of resistance to leptin naturally induce a rise in weight and the chances of insulin resistance. Once this scenario is installed, obesity chronifies the poor quality of the sleep, which is determinant for the appearance of the other components of MetS. ${ }^{10-11,15,19}$

In analyzing the components of MetS in isolation, with the exception of glycemia, none presented a statistically significant association or correlation with poor sleep quality. This fact diverges from the results of other studies found on the issue. ${ }^{9,12,14,20-24}$ However, it is appropriate to emphasize that none of these studies consulted investigated young adults. The youth of the university students, in principle, could protect them from the physiological decline which occurs with age and which can naturally predispose them to cardiovascular and metabolic changes.

This study's findings in relation to the association between poor sleep quality and raised FVBG diverge from the discourse of other researchers. These assert that this relation is independent of obesity and is predictive for prediabetes and type II diabetes mellitus (DM 2). Furthermore, in young adults, the presence of sleep problems and intolerance to glucose can reach $40 \%$, and the risk for DM2 increases five times in relation to those with healthy sleep..$^{18,29-31}$

According to speculation on the part of academics, the mechanism responsible for this is thought to be a rise in sympathetic activity and levels of cortisol, in combination with neuroendocrine imbalance of the satiogenic hormones in those who were poor sleepers. ${ }^{28,30-32}$ At any rate, these observations are fairly concerning, as they 
imply greater vulnerability of these young people in relation to DM 2. This disease is, nowadays, one of the main challenges for global public health. It is a matter of urgency that all health professionals should make a joint effort to curb any factor which can contribute to the rise in the risk for this disease. Hence, young adults' sleep quality should also be on the list of items to be evaluated in the prevention of DM 2.

Currently, poor sleep quality among university students is a global public health problem. In recent decades, the insertion of new technologies has transformed cultural habits and the lifestyle of university students worldwide and has contributed to the appearance of sleep disturbances among these young people. Some of their behaviors are determinant for sleep hygiene: irregular arrangement of sleeping times, prolonged naps during the day, the use of alcohol and electronic devices prior to sleeping, and studying in bed. ${ }^{33}$

In the practice in the health services, nurses habitually deal with issues related to human sleep, as observed in the nursing diagnoses of Improved sleep disposition and Sleep deprivation, above all in adults. However, it is strongly indicated that these issues should also be analyzed in schools and universities among the young population. In developed countries, school health is already a strong labor niche, but it remains incipient in Brazil. In the school environment, the nurse can contribute to the evaluation and monitoring of sleep quality, but particularly in the undertaking of health education actions, geared towards improving the sleep and duration of the sleep, the rest environment, and substance use.

\section{CONCLUSIONS}

There was an increase of $5 \%$ in the risk of developing MetS in the university students who were poor sleepers.

As this is a transversal study, one cannot establish causal relations. The research adopted a psychometric scale in evaluating the sleep quality of those studied, which, in spite of being equivalent, has a lower accuracy in relation to other analytical methods, such as polysomnography and actigraphy. In addition to this, the data of the PSQI were self-reported, that is, errors, facts which are untrue or little exact, due to memory faults, may have occurred.

Other limitations may be raised in the study design. A substantial percentage of university stu- dents mentioned not suffering sleep disturbances, however, the great majority slept alone. This limited the evaluation of the presence or absence of problems such as snoring or apnea, as well as their association with MetS. There was no control of the influence of the dietary pattern on the lipid levels. Neither was there association between the sleep quality with markers for vascular oxidation and hormones involved in energy metabolism.

As a result, it is recommended that this study should be replicated with university students of other localities and even nationalities, with longitudinal or experimental designs, so as to generate more robust evidence. It is advisable, furthermore, that, in addition to the components of MetS, associations should be established with the young peoples' chronotypes, markers for vascular oxidation and some hormones such as insulin, cortisol and somatotropin.

\section{REFERENCES}

1. Reaven GM. The metabolic syndrome: time to get off the merry-go-round? J Intern Med. 2011 Feb; 269(2):127-36.

2. Ram CV, Farmer JA. Metabolic syndrome in South Asians. J Clin Hypertens. 2012 Aug; 14(8):561-5.

3. Pan WH, Yeh WT, Weng, LC. Epidemiology of metabolic syndrome in Asia. Asia Pac J Clin Nutr. 2008 Jan; 17 (Supp 1):37-42.

4. Onyegbutulem HC, Onyegbutulem PI, Reimann M, Li J, Bornstein SR, Schwarz PE. Metabolic syndrome in Africa: an emerging perspective. Horm Metab Res. 2009 Feb; 41(2):75-8.

5. Ashraf H, Rashidi A, Noshad S, Khalilzadeh O, Esteghamati A. Epidemiology and risk factors of the cardiometabolic syndrome in the Middle East. Expert Rev Cardiovasc Ther. 2011 Mar; 9(3):309-20.

6. Carvalho-Vidigal F, Bressan J, Babio N, SalasSalvadó J. Prevalence of metabolic syndrome in Brazilian adults: a systematic review. BMC Public Health. 2013 Dec; 13:1198.

7. Dugan CE, Fernandez ML. Effects of dairy on metabolic syndrome parameters: a review. Yale J Biol Med. 2014 Jun 6; 87(2):135-47.

8. Poyrazoglu S, Bas F, Darendeliler F. Metabolic syndrome in young people. Curr Opin Endocrinol Diabetes Obes. 2014 Feb; 21(1):56-63.

9. Okubo N, Takahashi I, Sawada K, Sato S, Akimoto N, Umeda T, et al. Relationship between self-reported sleep quality and metabolic syndrome in general population. BMC Public Health. 2014 Jun, 14:562.

10. Drager LF, Lopes HF, Maki-Nunes C, Trombetta IC, Toschi-Dias E, Alves MJNN. The impact of obstructive sleep apnea on metabolic and 
inflammatory markers in consecutive patients with metabolic syndrome. Plos One. 2010 Aug, 5(8):12065.

11. Wolk R, Somers VK. Sleep and metabolic syndrome. Exp Physiol. 2007 Jan; 92: 67-78.

12. Mesas AE, Guallar-Castillón P, López-García E, León-Muñoz LM, Graciani A, Banegas JR, et al. Sleep quality and the metabolic syndrome: the role of sleep duration and lifestyle. Diabetes Metab Res Rev. 2014 Mar; 30(3):222-31.

13. Depner CM, Stothard ER, Wright KP Jr. Metabolic consequences of sleep and circadian disorders. Curr Diab Rep. 2014 Jul; 14(7):507.

14. Lee J, Choi YS, Jeong YJ, Lee J, Kim JH, Kim SH, et al. Poor-quality sleep is associated with metabolic syndrome in Korean adults. Tohoku Jour Exp Med. 2013 Dec; 231(4):281-91.

15. Hall MH, Muldon MF, Jennings JR, Buysse DJ, Flory JD, Manuck SB. Self-reported sleep duration is associated with metabolic syndrome in midlife adults. Sleep. 2008 May; 31(5):635-43.

16. Loponen M, Hublin C, Kalimo R, Mänttäri M, Tenkanen L. Joint effect of self-reported sleep problems and three components of the metabolic syndrome on risk of coronary heart disease. J Psychosom Res. 2010 Feb; 68(2):149-58.

17. Leineweber C, Keckclund G, Akerstedts T, Janszky I, Orth-Gomér K. Snoring and the metabolic syndrome in women. Sleep Med. 2003 Nov; 4: 531-6.

18. Jennings JR, Muldoon MF, Hall M, Buysse DJ, Manuck SB. Self-reported sleep quality is associated with the syndrome metabolic. Sleep. 2007 Feb; 30(2):219-23.

19. Schimid SM, Schultes B. Schlechter. Schlaf als risikofaktor für das metabolische syndrom. Der Internist. 2011 Apr; 52(11):383-8.

20. Yoo H, Franke WD. Sleep habits, mental health, and the metabolic syndrome in law enforcement officers. J Occup Environ Med. 2013 Jan; 55(1):99-103.

21. Kazman JB, Abraham PA, Zeno SA, Poth M, Deuster PA. Self-reported sleep impairment and the metabolic syndrome among African Americans. Ethn Dis. 2012 Dec; 22(4):410-5.

22. Countryman AJ, Saab PG, Llabre MM, Penedo FJ, McCalla JR, Schneiderman N. Cardiometabolic risk in adolescents: associations with physical activity, fitness, and sleep. Ann Behav Med. 2013 Feb; 45(1):121-31.
23. Hall MH, Okun ML, Sowers M, Matthews KA, Kravitz HM, Hardin K, et al. Sleep is associated with the metabolic syndrome in a multi-ethnic cohort of midlife women: the SWAN sleep study. Sleep 2012 Jun; 35(6):783-90.

24. Hung HC, Yang YC, Ou HY, Wu JS, Lu FH, Chang CJ. The association between self-reported sleep quality and metabolic syndrome. PLoS One 2013 Jan; 8(1):54304.

25. Bertolazi AN, Fagondes SC, Hoof L, Dartora EG, Miozzo IC, Barba ME, et al. Validation of the Brazilian Portuguese version of the Pittsburgh Sleep Quality Index. Sleep Med. 2011 Jan; 12(1):70-5.

26. Grundy SM, Cleeman JI, Daniels SR, Donato KA, Eckel RH, Franklin BA, et al. Diagnosis and management of the metabolic syndrome: an American Heart Association/National Heart, Lung, and Blood Institute Scientific Statement. Curr Opin Cardiol. 2006 Jan; 21(1):1-6.

27. Barros AJD, Hirakata VN. Alternatives for logistic regression in cross-sectional studies: an empirical comparison of models that directly estimate the prevalence ratio. BMC Med Res Methodol. 2003 Oct 20;3:21.

28. Tufik S. Medicina e biologia do sono. Barueri (SP): Manole; 2008.

29. Hancox, RJ, Landhus, C.E. Association between sleep duration and haemoglobin A1c in young adults. J Epidemiol Community Health. 2012 Oct; 66(10):957-61.

30. Ganwisch JE, Heymsfield SB, Boden-Albala B, Buijis RM, Kreier F, Pickering TG, et al. Sleep duration as a risk factor for diabetes incidence in a large US sample. Sleep. 2007 Dec; 30(12):1667-73.

31. Liu R, Zee PC, Chervin RD, Arquelles LM, Birne J, Zhang S. Short sleep duration is associated with insulin resistance independent of adiposity in Chinese adult twins. Sleep Med. 2011 Oct; 12(9): 914-9.

32. Knuston KL. Impact of sleep and sleep loss on glucose homeostasis and appetite regulation. Sleep Med Clin. 2007 Jun; 2(2):187-97.

33. Araújo MFM, Lima ACS, Araújo TM, Veras VS, Zanetti ML, Damasceno MMC. Relações entre fatores sociodemográficos e qualidade do sono em universitários brasileiros. Texto Contexto Enferm [online]. 2014 Mar [acesso 2014 Aug 30]; 23(1):176-84. Disponível em: http:/ / www.scielo.br/scielo.php?pid=S0104-07072014000100176\&script=sci_arttext 